\title{
Comparison of Upper Elbow Cast and Splint in Type II Supracondylar Humerus Fractures in Pediatric Patients
}

\author{
๑ Erhan Bayram, • Mahmud Aydin, ๑ Mehmet Ersin, • Mehmet Ekinci, ๑ Cem Yildirim, \\ (1) Murat Yilmaz \\ University of Health Sciences Turkey, Istanbul Haseki Training and Research Hospital, Clinic of Orthopedics and Traumatology, Istanbul, \\ Turkey
}

\section{Abstract}

\begin{abstract}
Aim: Most of the childhood elbow area fractures constitute supracondylar humerus fractures. The treatment approach in Gartland type II fractures is controversial. The purpose of our study was to compare the effectiveness of cast and splint in conservative treatment of type II supracondylar humerus fractures.
\end{abstract}

Methods: Sixty-nine pediatric patients admitted to our clinic due to gartland type II supracondylar humerus fractures between 2015 and 2020 were retrospectively evaluated. Closed reduction upper-elbow cast was applied to 26 patients, and closed reduction upperelbow splint treatment was applied to 43 patients. Radiological results of the patients were compared.

Results: The mean age of the patients participating in the study was $4.86 \pm 2.61$. Forty-two of 69 patients were male and 27 were female. Neurovascular deficit and compartment syndrome were not observed in any of the patients. When compared radiologically, no significant difference was found between the two groups.

Conclusion: Type II supracondylar humerus fractures, where conservative treatment is planned, the upper elbow casting or splint selected for immobilization shows similar effectiveness in protecting reduction.

Keywords: Humerus fracture, conservative treatment, classification

\section{Introduction}

Supracondylar humerus fractures constitute $30 \%$ of childhood fractures between the ages of two and eight years, and most of the fractures in the elbow area in childhood $(1,2)$. The Gartland classification is used in the classification of these fractures (3). This classification classifies non-displaced fractures as type I, fractures with varying degrees of displacement, but type II in which the posterior cortex is intact, displaced fractures in which the entire cortical connection is broken all around as type III.

In Gartland type I fractures, fixation in the position it is, and in Gartland type III fractures, open or closed reduction and pinning are the generally accepted treatment approaches (4-6). The treatment approach in type II fractures is controversial. Some authors recommend the closed reduction and pinning in all type II fractures with its success in achieving and maintaining reduction and low complication rates $(7,8)$. Some authors, on the other hand, argue that successful results are obtained in many patients with closed reduction and immobilization, therefore, avoiding the morbidity caused by surgical approach in this patient group would be a more appropriate approach $(9,10)$.

In our clinic, the Blount technique (closed reduction and immobilization) is used in the approach to type II supracondylar humerus fractures (11). For immobilization after reduction, an over-elbow circular cast or an overelbow splint is used in patient groups. The aim of this retrospective, radiological outcome study is to compare the effectiveness of the above-elbow plaster and splint in protecting the reduction achieved.

\section{Methods}

\section{Study Design}

Our study was prepared retrospectively in accordance with the ethical standards of the University of Health Sciences 
Turkey, Haseki Training and Research Hospital Clinical Research Ethics Committee and 1975 Helsinki Declaration revised in 2013, and the ethics committee approval was obtained (decision no: 2020-26, date: 26/02/2020). Since it is a retrospective study, only patient consent is available. Pediatric patients admitted to the emergency department between 2015 and 2020 and treated for supracondylar humerus fractures were scanned using hospital digital records and patient files. Patients with Gartland type I and type III fractures and other accompanying traumas were excluded from the study. Sixty-nine patients with non-surgically treated Gartland type II fractures, who had control films before, after reduction, and at the third week, followed up with an over-elbow splint or cast at $90^{\circ}$ after reduction, were included in the study (Figure 1). Demographic characteristics of the patients were noted. During the follow-up, the development of neurovascular complications and compartment syndrome was checked using hospital digital records and patient files. Depending on the preference of the treating surgeon, the patients were followed up with either an over-elbow circular cast or an over-elbow splint after reduction.

\section{Radiological Assessment}

Two researcher physicians accessed the pre-reduction, post-reduction and third-week graphs of the patients through the image archiving and communication system of our hospital. Baumann angle and anterior humeral line were used in radiological follow-up (Figure 2). The normal value was determined as $72 \pm 4$ as the Baumann angle. $10^{\circ}$ rotation in the humerus causes $6^{\circ}$ change in the Baumann angle. For this reason, a change greater than $6^{\circ}$ in post-reduction and final graphs was considered as a significant loss of position. Changes between $6^{\circ}-12^{\circ}$ were noted as mild, changes greater than $12^{\circ}$ were noted as severe reduction loss. On the lateral graph, the capitellum was divided into three equal parts and where the anterior humeral line intersected the capitellum was noted. Middle $1 / 3$ slice was considered normal. A one-slice change was considered a mild, two-slice change during follow-up was considered a serious loss of position.

\section{Statistical Analysis}

SPSS version 21.0 program was used for statistical analysis. While evaluating the study data, besides descriptive statistical methods (average, standard deviation, median, frequency, ratio, minimum, maximum), the Repeated Measures test (Variance Analysis in Repeated Measures) in the evaluation of the follow-up of the variables showing normal distribution in the comparison of quantitative data and Bonferroni test in the evaluation of paired comparisons Friedman test and Wilcoxon-Signed Ranks test were used to evaluate the follow-up of variables that did not show normal distribution. Significance was evaluated at the $p<0.05$ level.

\section{Results}

Sixty-nine patients were included in the study. After the reduction, 26 of the patients were followed with a cast and 43 with a splint. The mean age of the patients participating in the study was $4.86 \pm 2.61$ (1-12). 42 of 69 patients were male and 27 were female. Neurovascular deficit and compartment syndrome were not seen in any of the patients. The Baumann angle of 69 patients was $69.91 \pm 629$ before reduction, $69.85 \pm 5.46$ after reduction and $70.05 \pm 5.42$ at the $3^{\text {rd }}$ week follow-up. Again, when all patients were examined, before reduction, the anterior humeral line was anterior to the capitellum in 31 patients, the anterior $1 / 3$ of the capitellum in 33 patients, and the middle $1 / 3$ in 5 patients. After reduction, it was anterior to the capitellum in 14 patients, anterior $1 / 3$ in 41 patients, and middle $1 / 3$ in 14 patients. In the last follow-up, it was in front of the capitellum in 11 patients, in the anterior $1 / 3$ in 43 patients, and in the middle $1 / 3$ in 15 patients. Baumann angles belonging to the cast and splint group and the change in the intersection of the anterior humeral line with the capitellum are summarized in Table 1.

When the success in preserving the reduction obtained in the coronal plane in the splint and cast group

\begin{tabular}{|c|c|c|c|c|c|c|c|c|c|c|c|c|}
\hline & \multicolumn{4}{|c|}{ Before reduction } & \multicolumn{4}{|c|}{ After reduction } & \multicolumn{4}{|c|}{ Third week follow-up } \\
\hline & \multirow[b]{2}{*}{$\begin{array}{l}\text { Baumann } \\
\text { angel }\end{array}$} & \multicolumn{3}{|c|}{ Anterior humeral line } & \multirow[b]{2}{*}{$\begin{array}{l}\text { Baumann } \\
\text { angel }\end{array}$} & \multicolumn{3}{|c|}{ Anterior humeral line } & \multirow[b]{2}{*}{$\begin{array}{l}\text { Baumann } \\
\text { angel }\end{array}$} & \multicolumn{3}{|c|}{ Anterior humeral line } \\
\hline & & $\begin{array}{l}\text { Middle } \\
1 / 3\end{array}$ & $\begin{array}{l}\text { Anterior } \\
1 / 3\end{array}$ & $\begin{array}{l}\text { Anterior } \\
\text { to the } \\
\text { capitellum }\end{array}$ & & $\begin{array}{l}\text { Middle } \\
1 / 3\end{array}$ & $\begin{array}{l}\text { Anterior } \\
1 / 3\end{array}$ & $\begin{array}{l}\text { Anterior } \\
\text { to the } \\
\text { capitellum }\end{array}$ & & $\begin{array}{l}\text { Middle } \\
1 / 3\end{array}$ & $\begin{array}{l}\text { Anterior } \\
1 / 3\end{array}$ & $\begin{array}{l}\text { Anterior } \\
\text { to the } \\
\text { capitellum }\end{array}$ \\
\hline Cast & $69.11 \pm 7.41$ & 2 & 11 & 13 & $68.14 \pm 5.85$ & 0 & 13 & 13 & $67.58 \pm 4.40$ & 0 & 17 & 9 \\
\hline Splint & $70.39 \pm 5.55$ & 3 & 22 & 18 & $70.88 \pm 5.00$ & 14 & 28 & 1 & $71.55 \pm 5.49$ & 15 & 26 & 2 \\
\hline
\end{tabular}


was compared with the Baumann angle, no significant difference was found between the two groups $(p=0.743)$ (Table 2). When the radiological results of all patients were evaluated, it was found that reduction could be preserved in 58 patients (84\%), and serious reduction loss was found in only three patients (4\%). The quality and loss of reduction in the sagittal plane were followed by the anterior humeral line. Between the cast and splint groups, there was no significant difference between the groups in preserving the reduction obtained in the sagittal plane $(p=0.161)$ (Table 2). While no significant change was observed in the lateral graphy in 59 (86\%) of 69 patients, minimal reduction loss was observed in 10 patients (14\%).

\section{Discussion}

There is no consensus in the literature on the approach to Gartland type II fractures. Miranda et al. (12) reported in their study that they obtained radiological and functional results similar to those who were treated surgically in patients followed up with conservative treatment. Hadlow et al. (9) reported that surgical treatment of all type II fractures caused unnecessary surgical intervention in $77 \%$ of patients. Ojeaga et al. (13) described the factors affecting the success of conservative treatment in type II supracondylar humerus fractures and reported that conservative treatment had similar results to surgical treatment. Parikh et al. (5) experienced reduction loss in

\begin{tabular}{|c|c|c|c|c|}
\hline & & & & $p$ \\
\hline & & n (\%) & n (\%) & \\
\hline \multirow{3}{*}{$\begin{array}{l}\text { Anterior } \\
\text { humeral } \\
\text { line }\end{array}$} & $\begin{array}{l}\text { Reduction } \\
\text { preserved }\end{array}$ & 20 (76.9\%) & $21(80.8 \%)$ & 0.161 \\
\hline & $\begin{array}{l}\text { Minimal reduction } \\
\text { loss }\end{array}$ & $6(23.1 \%)$ & $4(15.4 \%)$ & \\
\hline & $\begin{array}{l}\text { Severe reduction } \\
\text { loss }\end{array}$ & $0(0.00 \%)$ & 1 (3.8\%) & \\
\hline \multirow{3}{*}{$\begin{array}{l}\text { Baumann } \\
\text { angle }\end{array}$} & $\begin{array}{l}\text { Reduction } \\
\text { preserved }\end{array}$ & 39 (90.7\%) & 37 (86\%) & 0.743 \\
\hline & $\begin{array}{l}\text { Minimal reduction } \\
\text { loss }\end{array}$ & 4 (9.3\%) & 4 (9.3\%) & \\
\hline & $\begin{array}{l}\text { Severe reduction } \\
\text { loss }\end{array}$ & $0(0.00 \%)$ & $2(4.7 \%)$ & \\
\hline
\end{tabular}

28 of the patients with type-two supracondylar humerus fractures they treated conservatively, and late surgical approach was required in $20 \%$ of the patients. In the radiological studies of Camus et al. (4), approximately half of the conservatively treated patients had rotational plane deformity in the coranal plane and sagittal plane deformity in $80 \%$, and they recommended a surgical approach in treatment. Morrison et al. (14) stated that the complication rate of surgical treatment is quite low contrary to popular belief and they advocated the surgical approach. Skaggs et al. (15) surgically treated all type II supracondylar humerus fractures in their study and did not observe any position loss in any patient, pin tract infection developed in $2.1 \%$ of the patients and secondary surgical intervention was required in $0.5 \%$ of the patients. They advocated a surgical approach in the treatment of these fractures due to low complication rates and better radiological results (15).

In the final follow-up of our study, the alignment of 58 patients $(84.05 \%)$ in the coronal plane was found to be within normal limits. The success rate was lower in the sagittal plane. In only 15 of the patients (21.7\%), the anterior humeral line passed through the middle $1 / 3$ of the capitellum. Although it is not sufficient by itself to demonstrate the reduction quality of the anterior humeral line, the success of conservative treatment in preventing extension deformity in the sagittal plane has been found to be lower than in the literature $(4,16)$. Although none of the patients had compartment syndrome or neurovascular injury seen as the positive side of conservative surgery, achieving and maintaining anatomical reduction was observed to be lower than surgical treatment.

When conservative treatment is chosen in type II supracondylar humerus fractures, the preferred method for immobilization is usually an above-elbow cast $(4,5,8)$. We compared the radiological results of these two patients groups to find out whether the above-elbow splint to be selected in the same patient group showed similar success in treatment in order to avoid difficulties in applying and removing the cast and to avoid possible complications such as compartment syndrome that may develop due to the cast. In both methods, the reduction obtained in more than $75 \%$ of the patients in the sagittal plane and more than $80 \%$ in the coronal plan could be preserved. While there was no serious loss of position in any patient in the sagittal plane, serious position loss was observed in one patient in the cast group in the coronal plane and in two patients in the splint group. There was no significant difference between groups in maintaining the reduction. This study shows that the above-elbow splint and cast used for immobilization after reduction in Gartland type II supracondylar humerus fractures are similarly effective in preserving reduction. Roberts et al. (17) compared cast and flexion-taping and immobilization in type II supracondylar humerus fractures and reported similar success rates in achieving and maintaining reduction in both patient groups. 
We did not find any study comparing immobilization with splint and cast in the same patient group in the literature. In this respect, we think that the results of our study will contribute to the literature.

\section{Limitations of the Study}

The most important limitation of our study is that it is a retrospective study. In addition, the fact that the patient groups are not determined randomly and the treatment is determined according to the surgeon's preference is another important limitation. Our limited number of patient groups makes it difficult to compare the rare complications according to the groups. A higher number of patient series are required to tell whether there is a difference between the groups in this regard. In addition, our study only evaluates radiological results. In order to compare both treatments, prospective randomized studies planned with a large number of patient series are needed in which functional results are examined.

\section{Conclusion}

In Gartland type II supracondylar humerus fractures, the success of conservative treatment to achieve anatomic reduction, especially in the sagittal plane, is low. In this group of patients for whom conservative treatment is planned, we believe that the above-elbow cast or splint selected for immobilization has a similar feature in protecting reduction.

\section{Authorship Contributions}

Concept: E.B., M.Y., Design: E.B., M.Y., M.A., Data Collection or Processing: M.A., M.Er., M.E., C.Y., Analysis or Interpretation: M.A., M.Er., M.E., C.Y., Literature Search: M.Er., M.E., C.Y., Writing: E.B.

Conflict of Interest: No conflict of interest was declared by the authors.

Financial Disclosure: The authors declared that this study received no financial support.

\section{References}

1. Crombie A, Duncan R. Closed reduction and percutaneous fixation of displaced paediatric supracondylar fractures of the elbow. Current Orthopaedics 2004;18:147-53.

2. Cheng JC, Ng BK, Ying SY, Lam PK. A 10-year study of the changes in the pattern and treatment of 6,493 fractures. J Pediatr Orthop 1999;19:344-50.

3. Mallo G, Stanat SJ, Gaffney J. Use of the Gartland classification system for treatment of pediatric supracondylar humerus fractures. Orthopedics 2010;33:19.
4. Camus T, MacLellan B, Cook PC, Leahey JL, Hyndman JC, ElHawary R. Extension type II pediatric supracondylar humerus fractures: a radiographic outcomes study of closed reduction and cast immobilization. J Pediatr Orthop 2011;31:366-71.

5. Parikh SN, Wall EJ, Foad S, Wiersema B, Nolte B. Displaced type II extension supracondylar humerus fractures: do they all need pinning? J Pediatr Orthop 2004;24:380-4.

6. Kropelnicki A, Ali AM, Popat R, Sarraf KM. Paediatric supracondylar humerus fractures. Br J Hosp Med (Lond) 2019;80:312-6.

7. Park MJ, Ho CA, Larson AN. AAOS Appropriate Use Criteria: Management of Pediatric Supracondylar Humerus Fractures. J Am Acad Orthop Surg 2015;23:52-5.

8. Spencer HT, Wong M, Fong YJ, Penman A, Silva M. Prospective longitudinal evaluation of elbow motion following pediatric supracondylar humeral fractures. I Bone Joint Surg Am 2010;92:904-10.

9. Hadlow AT, Devane P, Nicol RO. A selective treatment approach to supracondylar fracture of the humerus in children. J Pediatr Orthop 1996;16:104-6.

10. Minkowitz B, Busch MT. Supracondylar humerus fractures. Current trends and controversies. Orthop Clin North Am 1994;25:581-94.

11. BLOUNT WP. Fractures in children. Postgrad Med 1954;16:20916.

12. Miranda I, Sánchez-Arteaga P, Marrachelli VG, Miranda FJ, Salom M. Orthopedic versus surgical treatment of Gartland type II supracondylar humerus fracture in children. J Pediatr Orthop B 2014;23:93-9.

13. Ojeaga P, Wyatt CW, Wilson P, Ho CA, Copley LAB, Ellis HB Jr. Pediatric Type II Supracondylar Humerus Fractures: Factors Associated With Successful Closed Reduction and Immobilization. J Pediatr Orthop 2020;40:690-6.

14. Morrison SA, Pincus D, Camp MW. Complications of type II supracondylar humerus fractures treated at a specialized paediatric centre. Paediatr Child Health 2020;25:228-34.

15. Skaggs DL, Sankar WN, Albrektson J, Vaishnav S, Choi PD, Kay RM. How safe is the operative treatment of Gartland type 2 supracondylar humerus fractures in children? J Pediatr Orthop 2008;28:139-41.

16. Rogers LF, Malave S Jr, White H, Tachdjian MO. Plastic bowing, torus and greenstick supracondylar fractures of the humerus: radiographic clues to obscure fractures of the elbow in children. Radiology 1978;128:145-50.

17. Roberts L, Strelzow J, Schaeffer EK, Reilly CW, Mulpuri K. Nonoperative Treatment of Type IIA Supracondylar Humerus Fractures: Comparing 2 Modalities. I Pediatr Orthop 2018;38:521-6. 